\title{
A FAMília ARECACEAE (PALMEIRAS) NO MUNICÍPIO DE LAVRAS, MG
}

\author{
Joyce de Almeida Alves ${ }^{1}$, Douglas Antônio de Carvalho
}

(recebido: 16 de fevereiro de 2009; aceito: 26 de Fevereiro de 2010)

\begin{abstract}
RESUMO: Objetivou-se, neste trabalho, identificar as espécies de Arecaceae que ocorrem no município de Lavras, MG e elaborar uma chave analítica dicotômica para as espécies encontradas. O levantamento foi realizado em duas etapas: (1) levantamento nas principais praças e jardins (municipais e particulares); (2) levantamento das espécies ocorrentes às margens das estradas federais, estaduais e municipais que cortam o município de Lavras. As palmeiras encontradas foram fotografadas e identificadas in loco ou através de consultas a herbário e obras especializadas. Foram encontradas 38 espécies, das quais 5 são nativas, distribuídas em 25 gêneros. Os gêneros com maiores números de espécies foram Syagrus (6), Dypsis (3) e Roystonea (3), contribuindo com 31,58\% das espécies. As espécies nativas, Acrocomia aculeata e Syagrus romanzoffiana, ocorrem na maioria das margens das estradas percorridas. No levantamento realizado nas principais praças e jardins, destacaram-se as espécies do gênero Dypsis, Syagrus romanzoffiana, Phoenix roebelenii e Caryota urens.
\end{abstract}

Palavras-chave: Florística, taxonomia, sul de Minas Gerais.

\section{THE ARECACEAE FAMILY (PALM TREES) IN THE LAVRAS COUNTY, MG}

\begin{abstract}
This work identified the species of Arecaceae that occur in the County of Lavras, MG and elaborated a dichotomous analytical key for the species found. The survey was carried out in two stages: (1) survey the main squares and gardens (municipal and privately owned); (2) survey of the species close to the margins of the Lavras County federal, state and municipal highways. The palm trees found were photographed and identified in loco or through herbarium survey and related literature. Thirty nine species were found, 5 of which are native, distributed in 25 genera. The genera with the higher numbers of species were Syagrus (6), Dypsis (3) and Roystonea (3), making up 31.58\% of the species. The native species Acrocomia aculeata and Syagrus romanzoffiana occur in most edges of the travelled roads. In the survey done in the main squares and gardens, the species of the genus Dypsis, Syagrus romanzoffina, Phoenix roebelenii and Caryota urens stood out.
\end{abstract}

Key words: Floristic, taxonomy, South of Minas Gerais.

\section{INTRODUÇÃO}

As palmeiras possuem distribuição principalmente tropical e subtropical (MARTINS \& FILGUEIRAS, 2006). A maior ocorrência de gêneros e espécies verifica-se nas regiões tropicais da Ásia, Indonésia, Ilhas do Pacífico e Américas (LORENZI et al., 2004). Nas Américas são encontrados 67 gêneros e aproximadamente 1.440 espécies, das quais cerca de 200 espécies e 39 gêneros são registrados para o Brasil (HENDERSON et al., 1995).

As palmeiras são importantes para o homem, como fornecedoras de produtos, principalmente os alimentícios e também para a fauna, fornecendo abrigo e alimentação. Algumas espécies são de interesse paisagístico, por apresentarem grande diversidade de forma e tamanho das folhas e pela beleza de seus caules que podem ser revestidos por espinhos, fibras ou por bases remanescentes do pecíolo de folhas caídas (LORENZI et al., 1996). Embora as pesquisas sobre as Arecaceae tenham avançado nas últimas décadas, a maioria dos trabalhos florísticos e fitossociológicos realizados excluem essa família e isso se deve principalmente à metodologia aplicada (LIMA et al., 2003; ROCHA \& SILVA, 2005).

No município de Lavras, principalmente em trabalhos de inventários florestais, algumas espécies de Arecaceae já foram citadas, como Geonoma schottiana Mart. (DALANESI et al., 2004; NUNES et al., 2003), Syagrus flexuosa (Mart.) Becc. (DALANESI et al., 2004; NUNES et al., 2003), S. romanzoffiana (Cham.) Glassman (DALANESI et al., 2004; ESPÍRITO-SANTO et al., 2002; MACHADO et al., 2004; NUNES et al., 2003; SOUZA et al., 2003) e Euterpe edulis Mart. (ESPÍRITO-SANTO et al., 2002). Entretanto, nenhum levantamento criterioso sobre a ocorrência de palmeiras no município foi realizado.

\footnotetext{
${ }^{1}$ Graduanda em Engenharia Florestal, Bolsista PIBIC/CNPq - Departamento de Engenharia Florestal - Universidade Federal de Lavras - Cx. P. 3037 - 37200-000 - Lavras, MG - joyce_a.alves@yahoo.com.br

${ }^{2}$ Agrônomo, Professor Dr. em Biologia Vegetal - Departamento de Biologia - Universidade Federal de Lavras - Cx. P. 3037 - $37200-000$ Lavras, MG - douglasc@dbi.ufla.br
} 
Objetivou-se com este trabalho, identificar as espécies nativas e cultivadas de Arecaceae que ocorrem no município de Lavras, MG e elaborar uma chave de identificação para as espécies encontradas.

\section{MATERIAL E MÉTODOS}

\section{1 Área de Estudo}

O município de Lavras, com área de 564,50 km², localiza-se no sul de Minas Gerais, região do Alto Rio Grande, entre as coordenadas $21^{\circ} 06^{\prime}-21^{\circ} 25^{\prime} \mathrm{S}$ e $44^{\circ} 51^{\prime}$ $45^{\circ} 12^{\prime} \mathrm{W}$. A paisagem vegetacional nativa é composta pelos cerrados, campos cerrados, matas de galeria, matas de encosta e campos rupestres (QUEIROZ et al., 1980). Essa notável variação fisionômica da vegetação deve-se a dois motivos principais: a região abriga uma das áreas de transição entre os cerrados do Brasil Central e as florestas semidecíduas do sudeste e sul do País e esta transição ocorre em pleno domínio da serra da Mantiqueira, cujo relevo acidentado promove uma grande variação ambiental com fisionomias vegetais peculiares nas maiores altitudes. De uma maneira geral, as fisionomias de campo rupestre e campo de altitude estão associadas aos solos rasos e jovens do alto das montanhas, ao passo que, em altitudes menores, nos solos mais antigos e profundos, ocorrem cerrados ou florestas, discriminados pela fertilidade e regime de água dos solos e frequência de incêndios (OLIVEIRA-FILHO et al., 1994). De acordo com a classificação de Köppen (1948), o padrão climático é do tipo Cwa, temperado com inverno seco e verão chuvoso. As médias anuais de precipitação e temperatura são de $1.530 \mathrm{~mm}$ e $19,4^{\circ} \mathrm{C}$, respectivamente (BRASIL, 1992).

\subsection{Levantamento das espécies}

O levantamento foi realizado de agosto/2007 a janeiro/2008, por meio de visitas às principais praças $\mathrm{e}$ jardins (municipais e particulares) da cidade, visitas ao campus da Universidade Federal de Lavras (UFLA), revisão de literatura sobre levantamentos em fragmentos florestais do município e no Parque Ecológico Quedas do Rio Bonito (PEQRB) e percorrendo-se todas as estradas federais, estaduais e municipais que cortam o município.

As espécies foram fotografadas (aspecto geral $\mathrm{e}$ detalhes), identificadas in loco ou com ajuda de literatura especializada e/ou especialistas e tiveram as suas alturas máximas (altura estimada da base até o ponto mais alto das folhas) anotadas. A grafia do nome das espécies foi verificada a partir de consulta ao Index Kewensis (iwww.ipni.org/ipni/plantnamesearchpage.do e ao banco de dados do Missouri Botanical Garden, W3 Tropicos (Www. mobot.org/W3 3/Search/vast.htnll). A abreviação dos nomes de autores das espécies foi feita por consulta ao Brummitt \& Powell (1992) e ao MOBOT. Não foram feitas coletas de material botânico. Um CD contendo as fotos das espécies encontradas foi incorporado no Herbário ESAL, da Universidade Federal de Lavras. De acordo com a distribuição geográfica das espécies, citada nas literaturas, as mesmas foram incluídas em nativas e cultivadas. Foi elaborada uma chave analítica dicotômica para as espécies encontradas, utilizando-se características morfológicas vegetativas e/ou reprodutivas.

\section{RESULTADOS E DISCUSSÃO}

Foram encontradas 38 espécies, distribuídas em 25 gêneros (Tabela 1). Os gêneros com maior número de espécies foram Syagrus (6), Dypsis (3) e Roystonea (3), contribuindo com $31,58 \%$ das espécies. As espécies podem ser identificadas principalmente através de características vegetativas:

Chave analítica dicotômica para os gêneros e espécies de Arecaceae presentes no município de Lavras, MG:

1. Planta com caule subterrâneo ou muito curto. Sabal minor

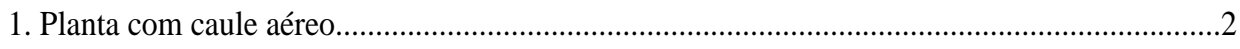

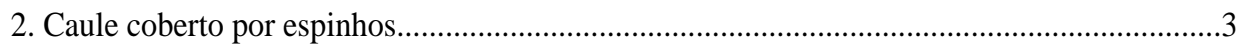

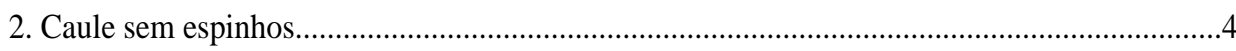

3. Caule coberto pelas bases remanescentes das folhas caídas.......... Acrocomia aculeata

3. Caule sem bases remanescentes das folhas caídas..................................Bactris gasipaes

Cerne, Lavras, v. 16, n. 2, p. 163-170, abr./jun. 2010 


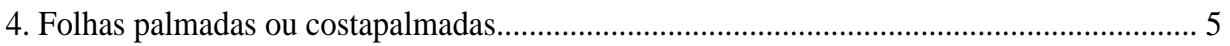

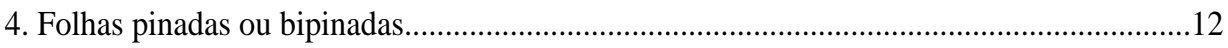

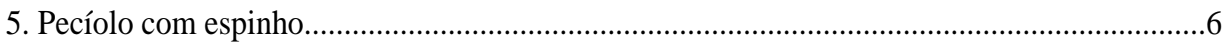

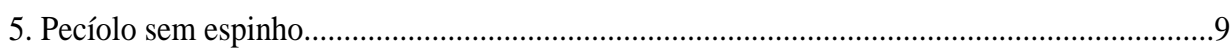

6. Frutos com mesocarpo alaranjado quando maduro............................Livistona chinensis

6. Frutos com mesocarpo de outra cor quando maduro......................................................

7. Planta com as folhas secas aderentes formando uma "saia"........Washingtonia robusta

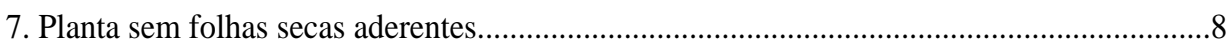

8. Folha em leque formando um círculo..........................................................ticuala grandis

8. Folha em leque formando um "V"..............................................................erops humilis

9. Caule cespitoso (múltiplo)..........................................................................Rhapis excelsa

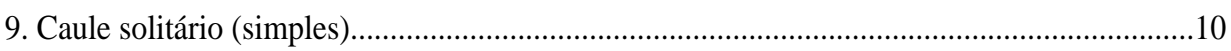

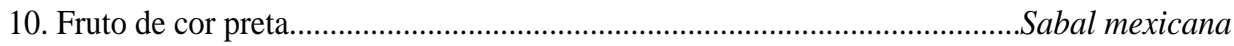

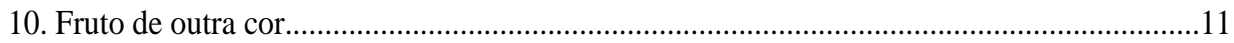

11. Folhas com segmentos rígidos......................................................Trachycarpus fortunei

11. Folhas com a extremidade dos segmentos pendula..............................Thrinax morrisii

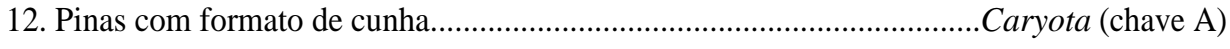

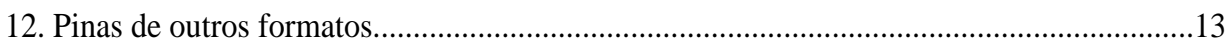

13. Folhas dispostas em quina triangular (trística)......................................Dypsis (chave B)

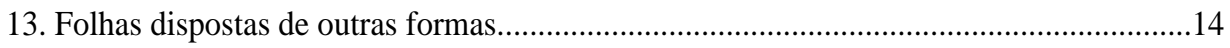

14. Pinas de formato sigmóide......................................................................edorea (chave C)

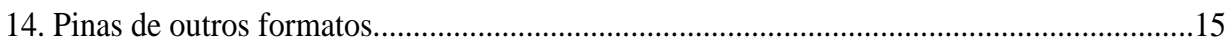

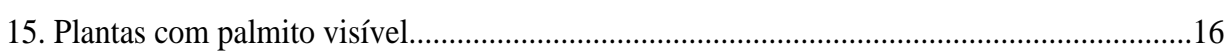

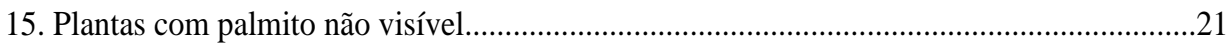

16. Inflorescência com ráquilas avermelhadas..............................................Pinanga kuhlii

16. Inflorescência com ráquilas verdes ou esbranquiçadas...............................................17

17. Fruto de cor preto - arroxeada........................................................................................... 18

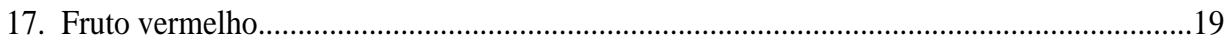

18. Frutos com epicarpo brilhante.....................................................................erpe edulis

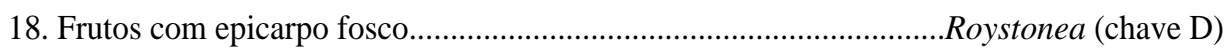

19. Pinas sem ápice denteado..............................................Archontophoenix cunninghamii

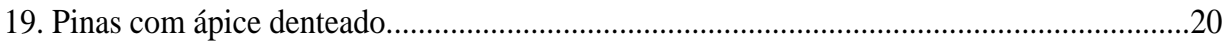

Cerne, Lavras, v. 16, n. 2, p. 163-170, abr./jun. 2010 
20. Frutos com 1,0-1,5 cm de comprimento Ptychosperma elegans

20. Frutos com 3,0-3,5 cm de comprimento. Veitchia montgomeryana

21. Pecíolo com espinhos.

21. Pecíolo sem espinhos.

22. Pecíolo com espinhos curvos

Syagrus schizophylla

22. Pecíolo sem espinhos retos.

23. Folhas de coloração verde-azulada Phoenix dactylifera

23. Folhas de coloração verde-brilhante. Phoenix roebelenii

24. Caule cespitoso .Syagrus flexuosa

24. Caule solitário. .25

25. Pinas com ápice torto e pêndulo Syagrus romanzoffiana

25. Pinas sem ápice torto e pêndulo .26

26. Frutos de cor preta quando maduro. Geonoma schottiana

26. Frutos de outra cor.

27. Folhas dispostas em 5 fileiras levemente torcidas. Syagrus coronata

27. Folhas dispostas de outra maneira. .28

28. Pinas de cor verde-prateada na face inferior Lytocaryum weddellianum

28. Pinas de outra cor na face inferior. .29

29. Pinas dispostas em mais de um plano. .30

29. Pinas dispostas em apenas um plano 31

30. Frutos ovóides com ápice pontiagudo Syagrus picrophylla

30. Frutos ovóides com ápice arredondado Syagrus oleracea

31. Fruto com epicarpo de cor marrom..... .Orbignya phalerata

31. Fruto de cor verde a amarelo Cocos nucifera

Chave A, para as espécies do gênero Caryota:

1. Plantas com caule solitário (simples) Caryota urens

1. Plantas com caule cespitoso (múltiplo). ..Caryota mitis

\section{Chave B, para as espécies do gênero Dypsis:}

1. Caule cespitoso. Dypsis lutescens

1. Caule solitário.

2. Pinas inseridas em ângulos diferentes. Dypsis madagascariensis

2. Pinas inseridas em ângulos iguais. Dypsis decaryi

Cerne, Lavras, v. 16, n. 2, p. 163-170, abr./jun. 2010 


\section{Chave C, para as espécies do gênero Chamaedorea:}

1. Raízes aéreas na base do caule. .Chamaedorea tepejilote

1. Ausência de raízes aéreas na base do caule. Chamaedorea microspadix

\section{Chave D, para as espécies do gênero Roystonea:}

1. Caule com dilatação central. Roystonea borinquena

1. Caule com dilatação irregular, levemente dilatado ou colunar. .2

2. Ramos secundários que partem da inflorescência são retilíneos............Roystonea regia

2. Ramos secundários que partem da inflorescência são sinuosos.....Roystonea oleracea

Das seguintes espécies, foram encontrados apenas um exemplar: Camaerops humilis L., Chamaedorea tepejilote Liebm., Lytocaryum weddellianum (H. Wendl.) Toledo, Sabal mexicana Mart., Syagrus coronata (Mart.) Becc., Syagrus oleracea (Mart.) Becc., Syagrus schizophylla (Mart.) Glassman, e Washingtonia robusta $\mathrm{H}$. Wendl. As espécies que mais se destacaram nas praças e jardins foram do gênero Dypsis Noronha ex Mart., Syagrus romanzoffiana, Phoenix roebelenii O'Brien e Caryota urens L. A utilização dessas espécies na arborização é observada em diversas regiões do Brasil (DANTAS \& SOUZA, 2004; HARDER, 2002; KURIHARA et al., 2005; SILVA et al., 2007).

Dentre as espécies citadas, cinco são nativas: Acrocomia aculeata Lodd. ex Mart., Euterpe edulis, Geonoma schottiana, Syagrus flexuosa e Syagrus romanzoffiana. As espécies Acrocomia aculeata e Syagrus romanzoffiana ocorrem, com frequência, nas margens das estradas percorridas; não ocorrem na divisa com o município de Itumirim, onde predominam os campos limpos e solos de baixa fertilidade (cambissolos háplicos) (CURI et al., 1990). Segundo Motta et al. (2002), a ocorrência de macaúba (Acrocomia aculeata) em Minas Gerais acompanha áreas de solos com maior fertilidade natural e vegetação primitiva de fisionomia florestal, indicando também preferência por áreas onde o déficit hídrico apresenta-se minimizado.

Euterpe edulis, Geonoma schottiana, Syagrus flexuosa e Syagrus romanzoffiana tiveram suas ocorrências relatadas em alguns levantamentos florísticos já realizados em Lavras. As espécies Geonoma schottiana, Syagrus flexuosa e Syagrus romanzoffiana ocorrem no Parque Ecológico Quedas do Rio Bonito (DALANESI et al., 2004) e na Reserva florestal da Universidade Federal de Lavras (NUNES et al., 2003). Na Mata da Subestação, ocorre Euterpe edulis e também Syagrus romanzoffiana, (ESPÍRITO-SANTO et al., 2002). Essa última ocorre ainda nos fragmentos de floresta estacional semidecidual montana localizados na Fazenda Beira Lago (MACHADO et al., 2004) e às margens do rio Capivari (SOUZA et al., 2003). Num trabalho realizado nos cerrados de uma região próxima à Lavras, o Sudoeste Mineiro, Carvalho \& Martins (2009) registraram a ocorrência de apenas duas palmeiras, ambas no município de Alpinópolis: Attalea geraensis Barb. Rodr., que não foi encontrada em Lavras, e Syagrus flexuosa.

Oliveira-Filho (2006) cita a ocorrência de 27 espécies de Arecaceae para o estado de Minas Gerais, distribuídas nos gêneros Acrocomia Mart., Astrocaryum G. Mey., Attalea Kunth, Bactris Jack. ex Scop., Butia Becc., Euterpe Mart., Geonoma Wild., Mauritia L.f., Mauritiella Burret, Polyandrococos Barb. Rodr. \& Barb. Rodr. e Syagrus Mart., sendo 17 classificadas como espécies de conservação raríssima, muito rara ou rara. Acrocomia aculeata, Syagrus romanzoffiana e Geonoma schottiana foram classificadas como frequentes e Euterpe edulis e Syagrus flexuosa como ocasionais em Minas Gerais.

Sabe-se que o clima é importante na determinação de gradientes de riqueza de palmeiras, limitando a sua distribuição a regiões tropicais e subtropicais com condições constantes de temperatura (amena a elevada) e umidade o ano inteiro (SALM et al., 2007). Compararam-se os resultados aqui obtidos para as espécies nativas, com outros levantamentos realizados no Brasil (Tabela 2). Verificou-se que o número de espécies nativas é maior em regiões de menores latitudes e/ou de elevada umidade, e que o município de Lavras apresenta um número de nativas condizente com a sua condição de marginal a esse ambiente ideal para o desenvolvimento natural das palmeiras. Entretanto, várias espécies plantadas (trinta e três) têm um desenvolvimento bastante satisfatório no município.

Cerne, Lavras, v. 16, n. 2, p. 163-170, abr./jun. 2010 


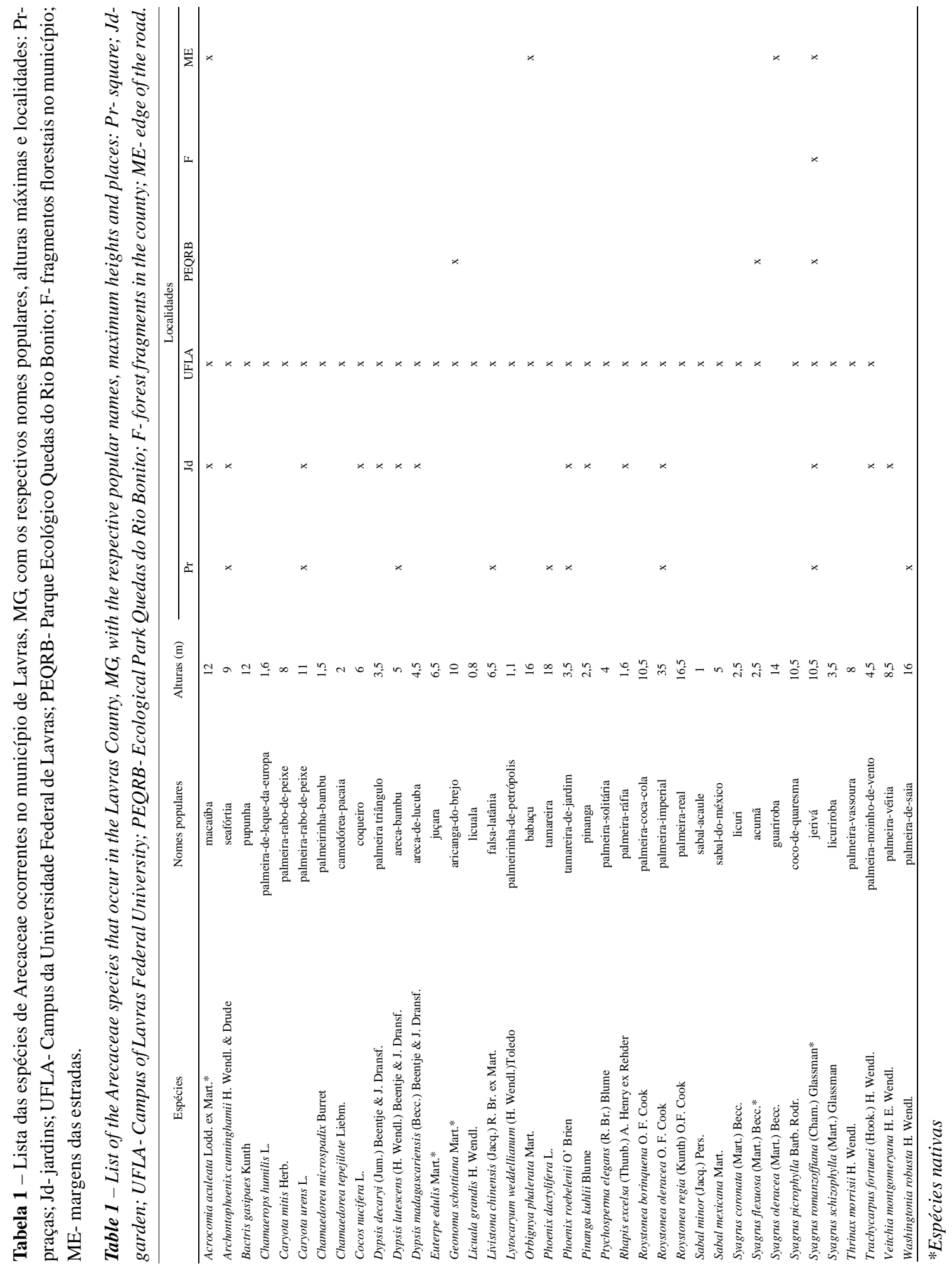

Cerne, Lavras, v. 16, n. 2, p. 163-170, abr./jun. 2010 
Tabela 2 - Comparação entre o levantamento das espécies nativas de Arecaceae realizado em Lavras, MG e em outras localidades. $\mathrm{EN}=$ número de espécies nativas encontradas; $\mathrm{EC}$ = espécies comuns com Lavras, MG.

Table 2 - Comparison among the surveys of the native Arecaceae species done in Lavras, $M G$ and in other places. EN = number of found native species; $E C=$ species in common with Lavras, $M G$.

\begin{tabular}{lccc}
\hline \multicolumn{1}{c}{ Locais } & EN & EC & Autor (es) \\
\hline $\begin{array}{l}\text { Cerrado sensu stricto, Fazenda } \\
\text { Água Limpa, DF. }\end{array}$ & 6 & Syagrus flexuosa & Lima et al. (2003) \\
Distrito Federal & 14 & $\begin{array}{c}\text { Acrocomia aculeata } \\
\text { Euterpe edulis } \\
\text { Syagrus flexuosa } \\
\text { Syagrus romanzoffiana }\end{array}$ & Martins \& Filgueiras (2006) \\
$\begin{array}{l}\text { Fragmentos de Floresta } \\
\text { secundária, Bragança, PA. }\end{array}$ & 14 & Rocha \& Silva (2005) \\
$\begin{array}{l}\text { Reserva Biológica da Represa do } \\
\text { Grama, Descoberto, MG. }\end{array}$ & 7 & Euterpe edulis \\
$\begin{array}{l}\text { Reserva Biológica, Cariacica, ES. } \\
\text { Restingas, RJ. }\end{array}$ & 16 & Syagrus romanzoffiana & Pivari \& Forzza (2004) \\
$\begin{array}{l}\text { Sub-bosque de terra firme na } \\
\text { Amazônia central, AM. }\end{array}$ & 11 & Geonoma schottiana \\
$\begin{array}{l}\text { Trecho de mata atlântica, Ubatuba, } \\
\text { SP. }\end{array}$ & 11 & Euterpe edulis & Lima \& Soares (2003) \\
\hline
\end{tabular}

\section{REFERÊNCIAS BIBLIOGRÁFICAS}

BRASIL. Ministério da Agricultura e da Reforma Agrária. Departamento Nacional de Meteorologia. Normais Climatológicas: 1961-1990. Brasília, 1992. 84 p.

BRUMMITT, R. K.; POWELL, C. E. Authors of plant names. Kew: Royal Botanical Garden, 1992.

CARVALHO, D. A.; MARTINS, F. R. Shrub and tree species composition in the cerrados of southwest Minas Gerais. Cerne, Lavras, v. 15, n. 2, p. 142-154, 2009.

CURI, N.; LIMA, J. M.; ANDRADE, H.; GUALBERTO, V. Geomorfologia, física, química e mineralogia dos principais solos da região de Lavras (MG). Revista Ciência e Prática, Lavras, v. 14, n. 3, p. 297-307, set./dez. 1990.

DALANESI, P. E.; OLIVEIRA-FILHO, A. T.; FONTES, M. A. L. Flora e estrutura do componente arbóreo da floresta do Parque Ecológico Quedas do Rio Bonito, Lavras, MG, e correlações entre a distribuição das espécies e variáveis ambientais. Acta Botanica Brasilica, São Paulo, v. 18, n. 4, p. 737-757, 2004.

DANTAS, I. C.; SOUZA, C. M. C. Arborização urbana na cidade de Campina Grande-PB: inventário e suas espécies. Revista de Biologia e Ciências da Terra, Campina Grande, v. 4, n. 2, 2004.

ESPÍRITO-SANTO, F. D. B.; OLIVEIRA-FILHO, A. T.; MACHADO, E. L. M.; SOUZA, J. S.; FONTES, M. A. L.; MELO-MARQUES, J. J. G. S. Variáveis ambientais e a distribuição de espécies arbóreas em um remanescente de floresta estacional semidecídua montana no campus da Universidade Federal de Lavras (UFLA), MG. Acta Botanica Brasilica, São Paulo, v. 16, n. 3, p. 331-356, 2002.

HARDER, I. C. F. Inventário quali-quantitativo da arborização e infra-estrutura das praças da cidade de Vinhedo, SP. 2002. 122 p. Dissertação (Mestrado em Agronomia) Escola Superior de Agricultura "Luiz de Queiroz”, Piracicaba. 
HENDERSON, A.; GALEANO, G.; BERNAL, R. Field guide to the palms of the americas. New Jersey: Princeton University, 1995. $352 \mathrm{p}$.

KÖPPEN, W. Climatologia: con un estudio de los climas de la tierra. México: Fondo Cultura Economica, 1948. 478 p.

KURIHARA, D. L.; IMAÑA-ENCINAS, J.; PAULA, J. E. de. Levantamento da arborização do campus da Universidade de Brasília. Cerne, Lavras, v. 11, n. 2, p. 127-136, 2005.

LIMA, A. L.; SOARES, J. J. Aspectos florísticos e ecológicos de palmeiras (Arecaceae) da Reserva Biológica de Duas Bocas, Cariacica, Espírito Santo. Boletim Museu de Biologia Prof. “Mello Leitão”, Santa Teresa, v. 16, p. 5-20, 2003.

LIMA, E. S.; FELFILI, J. M.; MARIMON, B. S.; SCARIOT, A. Diversidade, estrutura e distribuição espacial de palmeiras em um cerrado sensu stricto no Brasil Central-DF. Revista Brasileira de Botânica, São Paulo, v. 26, n. 3, p. 361-370, 2003.

LORENZI, H.; SOUZA, H. M.; MEDEIROS-COSTA, J. T. Palmeiras do Brasil: nativas e exóticas. Nova Odessa: Instituto Plantarum de Estudos da Flora, 1996. 303 p.

LORENZI, H.; SOUZA, H. M.; MEDEIROS-COSTA, J. T.; CERQUEIRA, L. S. C.; FERREIRA, E. Palmeiras brasileiras e exóticas cultivadas. Nova Odessa: Instituto Plantarum de Estudos da Flora, 2004. 416 p.

MACHADO, E. L. M.; OLIVEIRA-FILHO, A. T.; CARVALHO, W. A. C.; SOUZA, J. S.; BORÉM, R. A. T.; BOTEZELLI, L. Análise comparativa da estrutura e flora do compartimento arbóreo-arbustivo de um remanescente florestal na fazenda Beira Lago, Lavras, MG. Revista Árvore, Viçosa, v. 28, n. 4, p. 499516, 2004.

MARTINS, R. C.; FILGUEIRAS, T. S. Arecaceae. In: CAVALCANTI, T. B. Flora do Distrito Federal, Brasil. Brasília: Embrapa Recursos Genéticos e Biotecnologia, 2006. p. 47-82.

MOTTA, P. E. F.; CURI, N.; OLIVEIRA-FILHO, A. T.; GOMES, J. B. V. Ocorrência de macaúba em Minas Gerais: relação com atributos climáticos, pedológicos e vegetacionais. Pesquisa Agropecuária Brasileira, Brasília, v. 37, n. 7, p. 1023-1031, 2002.

NUNES, Y. R. F.; MENDONÇA, A. V. R.; OLIVEIRA-FILHO, A. T.; BOTEZELLI, L.; MACHADO, E. L. M. Variações da fisionomia, diversidade e composição de guildas da comunidade arbórea em um fragmento de floresta semidecidual em Lavras, MG. Acta Botanica Brasilica, Porto Alegre, v. 17, n. 2, p. 213-229, 2003.

Cerne, Lavras, v. 16, n. 2, p. 163-170, abr./jun. 2010
OLIVEIRA, A. N.; AMARAL, I. L. Aspectos florísticos, fitossociológicos e ecológicos de um sub-bosque de terra firme na Amazônia central, Amazonas, Brasil. Acta Amazonica, Manaus, v. 35, n. 1, p. 1-16, 2005.

OLIVEIRA-FILHO, A. T. Catálogo das árvores nativas de Minas Gerais. Lavras: UFLA, 2006. 423 p.

OLIVEIRA-FILHO, A. T.; VILELA, E. A.; GAVILANES, M. L.; CARVALHO, D. A. Comparison of the Woody flora and soils of six areas of montane semideciduous forest in southern Minas Gerais, Brazil. Edinburgh Journal of Botany, Edinburgh, v. 51, n. 3, p. 355-389, 1994.

PIVARI, M. O.; FORZZA, R. C. A. Família palmae na reserva biológica da represa do grama: descoberto, Minas Gerais, Brasil. Rodriguésia, Rio de Janeiro, v. 55, n. 85, p. 115-124, 2004.

QUEIROZ, R.; SOUZA, A. G.; SANTANA, P.; ANTUNES, F. Z.; FONTES, M. Zoneamento agroclimático do Estado de Minas Gerais. Belo Horizonte: Secretaria do Estado da Agricultura, 1980. $114 \mathrm{p}$.

REIS, R. C. C. Palmeiras (Arecaceae) das restingas do estado do Rio de Janeiro, Brasil. Acta Botanica Brasilica, São Paulo, v. 20, n. 3, p. 501-512, 2006.

ROCHA, A. E. S.; SILVA, M. F. F. Aspectos fitossociológicos, florísticos e etnobotânicos das palmeiras (Arecaceae) de floresta secundária no município de Bragança, PA, Brasil. Acta Botanica Brasilica, São Paulo, v. 19, n. 3, p. 657-667, 2005.

SALM, R.; SALLES, N. V.; ALONSO, W. J.; SCHUCK-PAIM, C. Cross-scale determinants of the palm species distribution. Acta Amazonica, Manaus, v. 37, n. 1, p. 17-26, 2007.

SILVA, K. M. M.; CHAGAS, N. J. H.; CARNEIRO, A. R. S.; BARRETO, R. C. Inventário da vegetação cultivada na Praça da República: um estudo para a conservação e tombamento dos Jardins de Burle Marx. Revista Brasileira de Biociências, Porto Alegre, v. 5, n. 1, p. 396-398, 2007.

SOUZA, J. S.; ESPÍRITO-SANTO, F. D. B.; FONTES, M. A. L.; OLIVEIRA-FILHO, A. T.; BOTEZELLI, L. Análise das variações florísticas e estruturais da comunidade arbórea de um fragmento de floresta semidecídua às margens do rio Capivari, Lavras - MG. Revista Árvore, Viçosa, v. 27, n. 2, p. 185-206, 2003.

TOLEDO, M. C. B.; FISCH, S. T. V. Bases cartográficas para armazenamento e análise espacial de dados da diversidade de palmeiras em um trecho de Mata Atlântica, Ubatuba-SP. Biota Neotropica, Campinas, v. 6, n. 1, 2006. Disponível em: <http:// [www.biotaneotropica.org.br/v5n1/pt/s. Acesso em: 10 fev. 2009. 